\title{
MiRNA-149 modulates chemosensitivity of (rossank ovarian cancer A2780 cells to paclitaxel by targeting MyD88
}

\author{
Yueping Zhan ${ }^{1 \dagger}$, Fenfen Xiang ${ }^{2 \dagger}$, Rong $\mathrm{Wu}^{2}$, Jian $\mathrm{Xu}^{1}$, Zhenhua $\mathrm{Ni}^{1}$, Jiemin Jiang ${ }^{2}$ and Xiangdong Kang ${ }^{1,2^{*}}$
}

\begin{abstract}
Background: The low effectiveness of anticancer drugs remains a major unresolved obstacle to successful chemotherapy. Recently, much evidence on the roles of miRNAs in determining drug-sensitivity/resistance has been emerging. The relationship between miRNA-149 expression and paclitaxel chemoresistance in human ovarian cancer cells remains largely unknown.

Methods: This study investigated the relationship between miRNA-149 expression and the sensitivity of ovarian cancer A2780 cells to paclitaxel treatment. To achieve the down-regulation of miRNA-149 gene expression in A2780 cell line, the cells were infected with lentivirus carrying inhibitor of miRNA-149. Western blot and qRT-PCR were used to detect relevant protein levels and the expressions of mRNAs of interest. Cell proliferation was measured by CCK-8 assay. Flow cytometry was used to measure cell cycle and apoptosis. Transwell migration assay was used to observe the change of migration of transfected cells.

Results: Down-regulation of miRNA-149 decreased the sensitivity of ovarian cancer A2780 cells to paclitaxel. After paclitaxel treatment, decreased apoptosis and G2 phase ratio, increased cell migration, increased level of Bcl-2, and decreased level of Bax were found in miRNA-149-down-regulated A2780 cells. MiRNA-149 down-regulation resulted in increased expression of MyD88 in A2780 cells. Down-regulation of miRNA-149 in A2780 cells increased MyD88 expression and decreased their sensitivity to paclitaxel treatment.
\end{abstract}

Conclusion: Our findings suggest that miRNA-149 mediates the susceptibility of paclitaxel by regulating MyD88 expression in ovarian cancer cells.

Keywords: miRNA-149, MyD88, Paclitaxel, Chemosensitivity, Ovarian cancer

\section{Introduction}

Ovarian cancer is a common tumor and the most lethal malignancy of the female reproductive organs. A combination of carboplatin and paclitaxel has been widely used as chemotherapy for ovarian cancer patients. Although the patients initially respond successfully to paclitaxel-based chemotherapy, in most cases, they eventually become insensitive to the chemotherapy [1]. Several mechanisms have been demonstrated regarding chemoresistance to paclitaxel, such as over-expression of the multidrug transporter P-

\footnotetext{
*Correspondence: xd_kang@msn.com

${ }^{\dagger}$ Equal contributors

'Department of Central Lab, Putuo Hospital, Shanghai University of Traditional Chinese Medicine, Shanghai 200062, P.R. China

${ }^{2}$ Department of Laboratory Medicine, Putuo Hospital, Shanghai University of Traditional Chinese Medicine, Shanghai 200062, P.R. China
}

glycoprotein [2], selective expression of beta-tubulin isotypes [3], down-regulation of bcl-2 [4], or aberrant cell signaling [5]. Nevertheless, the overall molecular mechanisms of paclitaxel resistance have yet to be clarified.

MicroRNAs (miRNAs) are a family of short noncoding RNAs that negatively regulate gene expression at the post-transcriptional level. Hundreds of miRNAs have been found in the human genome and play critical roles in regulating cell signaling pathways such as the transforming growth factor-beta, Wnt, Notch and epidermal growth factor pathways by repressing the expression of different mRNAs expression or through co-regulation with transcription factors [6-9]. Consequently, dysfunction of miRNAs and their target genes can lead to a variety of disorders. Therefore studying the role of 
miRNAs will provide a better understanding of the molecular events involved in diverse biological processes, and contribute to the identification of new targets in tumor prevention and treatment.

MiRNA-149 directly targets the 3'-UTR of MyD88 mRNA and post-transcriptionally regulates MyD88 protein expression. MiRNA-149 may be a key modulator in the TLR/MyD88 signaling pathway in macrophages through negative regulation of MyD88-dependent Toll-like receptor signaling [10]. In our previous study, the expression of MyD88 was closely associated with paclitaxel resistance in lung cancer A549 cells [11].

The relationship between miRNA-149 expression and paclitaxel chemoresistance in human ovarian cancer cells remains largely unknown. In this study, we investigated whether miRNA-149 modulates cellular sensitivity to paclitaxel by regulating the expression of MyD88 in ovarian cancer A2780 cells.

\section{Materials and methods}

\section{Cell line and maintenance}

The A2780 cell line was obtained from the Institute of Cell Biology (Shanghai, China). The cells were maintained in RPMI 1640 medium (Gibco-BRL, Carlsbad, CA, USA) supplemented with $10 \%$ fetal bovine serum (FBS), $100 \mathrm{U} / \mathrm{ml}$ penicillin and $100 \mathrm{U} / \mathrm{ml}$ streptomycin at $37{ }^{\circ} \mathrm{C}$ in a humidified incubator with $5 \% \mathrm{CO}_{2}$. The cells were demonstrated to be free of mycoplasma.

\section{Construction of miRNA-149 inhibitor and MyD88 lentiviral vectors}

MiRNA-149 inhibitor (5'-GGGAGUGAAGACACGGAG CCAGA-3') was inserted into the LV3-pGLV-H1-GFP/puro lentiviral vector, and siRNA (5'-UUCUCCGAACGUGUCACGUdTdT-3') was used as a negative control. MyD88 whole cDNA synthesized by GenePharma (GenePharma, Shanghai, China) was subcloned into the LV5pGLV-EF1a-GFP/Puro Lentiviral plasmid vector. Lentiviruses expressing inhibitor against miRNA-149, MyD88, and the controls were produced by co-transfection of $293 \mathrm{~T}$ cells using polybrene (GenePharma, Shanghai, China) according to standard protocols. A2780 $\left(5 \times 10^{4}\right)$ cells were infected with lentivirus at a MOI (multiplicity of infection, pfu number/cell) of approximately 100 for 24 h. Cells were then transferred into complete medium.

\section{RNA isolation and reverse transcription polymerase chain reaction (RT-PCR)}

Small RNAs were purified from differently treated A2780 cells using an RNA purification kit (TIANGEN Biotech, Beijing, China). Total RNA was extracted with Trizol reagent according to the protocol described by the supplier (TakaRa, Dalian, China). First-strand cDNA was synthesized from $1 \mu \mathrm{g}$ of total RNA in a $20-\mu \mathrm{l}$ reaction mixture using the PrimeScript RT reagent kit (TakaRa, Dalian, China). Quantitative real-time PCR-based gene expression analysis was performed on a real-time PCR instrument (7300, Step One Plus, Applied Biosystems, USA) using a standard SYBR-Green PCR kit. The parameters used for all PCR reactions were as follows: One cycle of $95^{\circ} \mathrm{C}$ for $2 \mathrm{~min}$, followed by 40 cycles of $95^{\circ} \mathrm{C}$ for $15 \mathrm{~s}$, and $60{ }^{\circ} \mathrm{C}$ for $30 \mathrm{~s}$. Specific primer sets were used for RT-PCR of the U6 control, miR-149, $\beta$-actin control, and MyD88. The relative expression of each target gene was calculated using the $2^{-\Delta \Delta \mathrm{ct}}$ method.

\section{Analysis of apoptosis}

The percentage of apoptotic cells was quantitated using the Annexin V-PE Kit (Becton-Dickinson) according to the manufacturer's instructions. Stained cells were analyzed by flow cytometry during the first $30 \mathrm{~min}$ of staining. $\geq 10,000$ cells were measured using a FACScan instrument (Becton-Dickinson) and the data were analyzed using FlowJo software (Tree Star Inc.).

\section{Cytotoxicity assay}

Cell viability was assessed using the Cell Counting Kit 8 (CCK-8) (Dojindo Laboratories, Kumamoto, Japan) assay. $6 \times 10^{4}$ A2780 cells $(100 \mu \mathrm{l})$ were seeded into 96-well plates. After $24 \mathrm{~h}$ of incubation, paclitaxel (Sigma) was added at concentrations of $0 \mu \mathrm{M}, 0.1 \mu \mathrm{M}, 0.2 \mu \mathrm{M}, 0.3 \mu \mathrm{M}$, $0.4 \mu \mathrm{M}$ and $0.5 \mu \mathrm{M}$ (each concertration were done repeat five experiments); the cells were then incubated for $48 \mathrm{~h}$. After $48 \mathrm{~h}, 10 \mu \mathrm{l}$ of CCK-8 solution was added to each well, followed by $4 \mathrm{~h}$ of incubation at $37{ }^{\circ} \mathrm{C}$. The OD values were read at dual wave lengths of $450 \mathrm{~nm}$ and $630 \mathrm{~nm}$ to determine cell viability using a microplate reader (Thermo Fisher Labsystems).

\section{Analysis of cell cycle}

Cells $\left(2 \times 10^{6}\right)$ were pelleted by spinning for $5 \mathrm{~min}$ at $1000 \mathrm{rpm}$ and $4{ }^{\circ} \mathrm{C}$ and resuspended in $1 \mathrm{ml}$ of cold PBS. After fixation by adding $4 \mathrm{ml}$ of absolute ethanol, the cells were centrifuged and resuspended in $1 \mathrm{ml}$ of PBS. Then, $100 \mu \mathrm{l} \mathrm{of} 200 \mu \mathrm{g} / \mathrm{ml}$ DNase-free RNaseA was added to the cell suspension and incubated for $30 \mathrm{~min}$ at $37^{\circ} \mathrm{C}$. The cells were stained with $100 \mu \mathrm{l}$ of $1 \mathrm{mg} / \mathrm{ml}$ propidium iodide (light sensitive) and incubated for 5-10 $\mathrm{min}$ at room temperature before analysis.

\section{Western blot}

The protein concentration of each sample was determined by BCA Protein Assay Kit (Beyotime, Jiangsu, China). Equal amounts of protein were loaded and separated discontinuously on $12 \%$ sodium dodecyl sulfate-polyacrylamide gels (SDS-PAGE), and subsequently transferred onto a PVDF membrane (Amersham Pharmacia, UK). The membrane was then incubated in TBST blocking solution 
(Tris-buffered saline including $0.1 \%$ Tween-20) containing $5 \%$ skim milk for $2 \mathrm{~h}$ at room temperature, followed by separate incubation with primary antibodies against Bax, MyD88, Bcl-2 (Cell Signaling, USA) and $\beta$ actin (Beyotime, Jiangsu, China) overnight at $4{ }^{\circ} \mathrm{C}$. After washing, the membrane was incubated with HRPconjugated anti-mouse, anti-rabbit, or anti-goat secondary antibodies for $2 \mathrm{~h}$. After several washes, the immunoblot was detected with enhanced chemi-luminescence reagent (Pierce Biotechnology, USA) according to the manufacturer's instructions.

\section{Immunocytochemistry}

Expression of MyD88 protein was determined using immunocytochemistry. In total, $1 \times 10^{5}$ cells were seeded into a Millicell EZ Slide (Millipore, Shanghai, China). After $24 \mathrm{~h}$ of incubation, cells were fixed on slides using $4 \%$ paraformaldehyde. The cells were permeabilized for 10 min with $0.1 \%$ Triton X-100 in PBS and blocked with blocking buffer (2\% BSA, $0.1 \%$ Triton X-100) for $30 \mathrm{~min}$ at room temperature. After blocking, the cells were washed with PBS and incubated overnight with rabbit anti-human MyD88 antibodies (Sigma, Shanghai, China) at $4{ }^{\circ} \mathrm{C}$. On the following day, the cells were washed three times with PBS, and then incubated with Cy3-labeled goat anti-rabbit IgG $(\mathrm{H}+\mathrm{L})$ (Beyotime, China) for $1 \mathrm{~h}$ followed by washing with PBS three times.

\section{Cell migration assay}

Cell migration were evaluated using the Transwell Permeable Support (Corning) according to the manufacturer's instructions. Five 200-multiple microscopic fields were randomly selected to calculate the total count of the invaded or migrated cells. All assays were conducted three times.

\section{Statistical analysis}

For all analyses, the measurements obtained from the groups were expressed as the means \pm SD for all data determined. Statistical analysis was performed using an unpaired Student's t-test followed by Tukey's test. $\mathrm{P}<0.05$ was considered statistically significant.

\section{Results}

\section{Decreased sensitivity of A2780 cells to paclitaxel}

\section{treatment after down-regulation of miRNA-149}

We used a lentiviral vector expressing inhibitor against miRNA-149 to achieve down-regulation of miRNA-149 in ovarian cancer A2780 cells. Real-time PCR analysis showed that the expression of miRNA-149 in cells transduced with inhibitor to miRNA-149 was markedly lower than that of control A2780 cells (Fig. 1a). In the presence of paclitaxel, the proliferation of A2780 cells was significantly inhibited in the control (Fig. 1b), suggesting that down-regulation of miRNA-149 decreased the sensitivity of A2780 cells to paclitaxel treatment.

\section{Down-regulation of miRNA-149 increases the expression of MyD88 in A2780 cells}

Using miRanda (http://www.microrna.org/) and TargetScan (http://www.targetscan.org/) to analysis the miRNA-149 target sites of MyD88 (Fig. 2a). To assess whether miRNA-149 is involved in the regulation of MyD88 expression in A2780 cells, the expression of MyD88
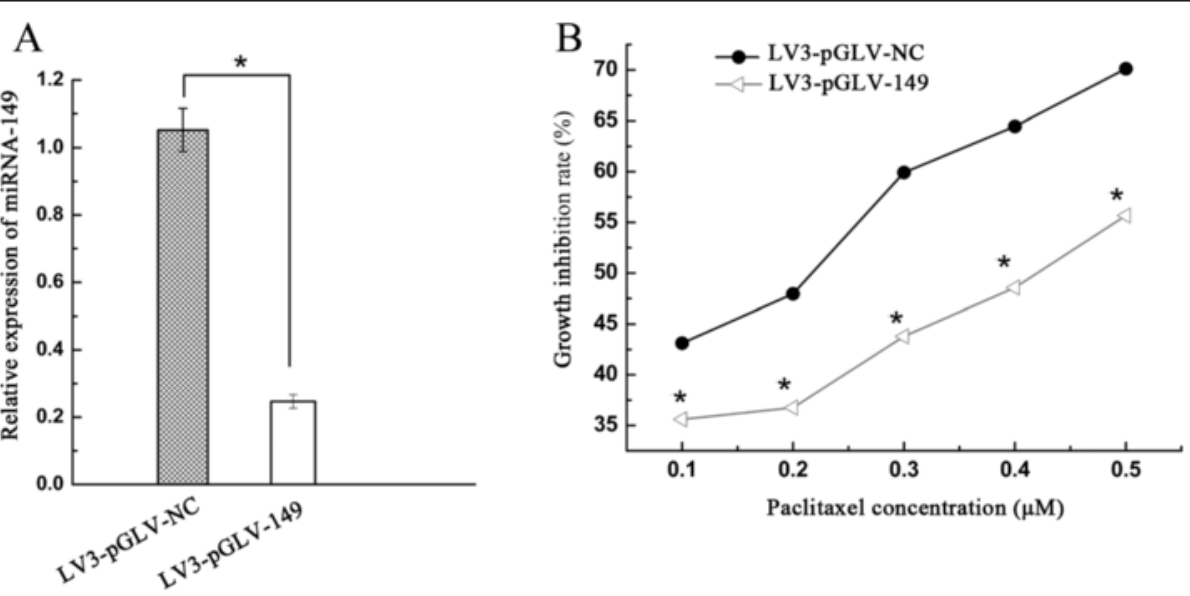

Fig. 1 Inhibition of cell growth by paclitaxel was determined in A2780 cells after miRNA-149 knockdown. Paclitaxel treatment was conducted for $48 \mathrm{~h}$ with the indicated concentrations. a The expression level of miRNA-149 was measured using quantitative real-time PCR in different groups. Asterisk refers to $p<0.01$. b The inhibition of cell growth by paclitaxel was determined in A2780 cells after miRNA-149 down-regulation. Paclitaxel treatment was performed for $48 \mathrm{~h}$ with the indicated concentrations 


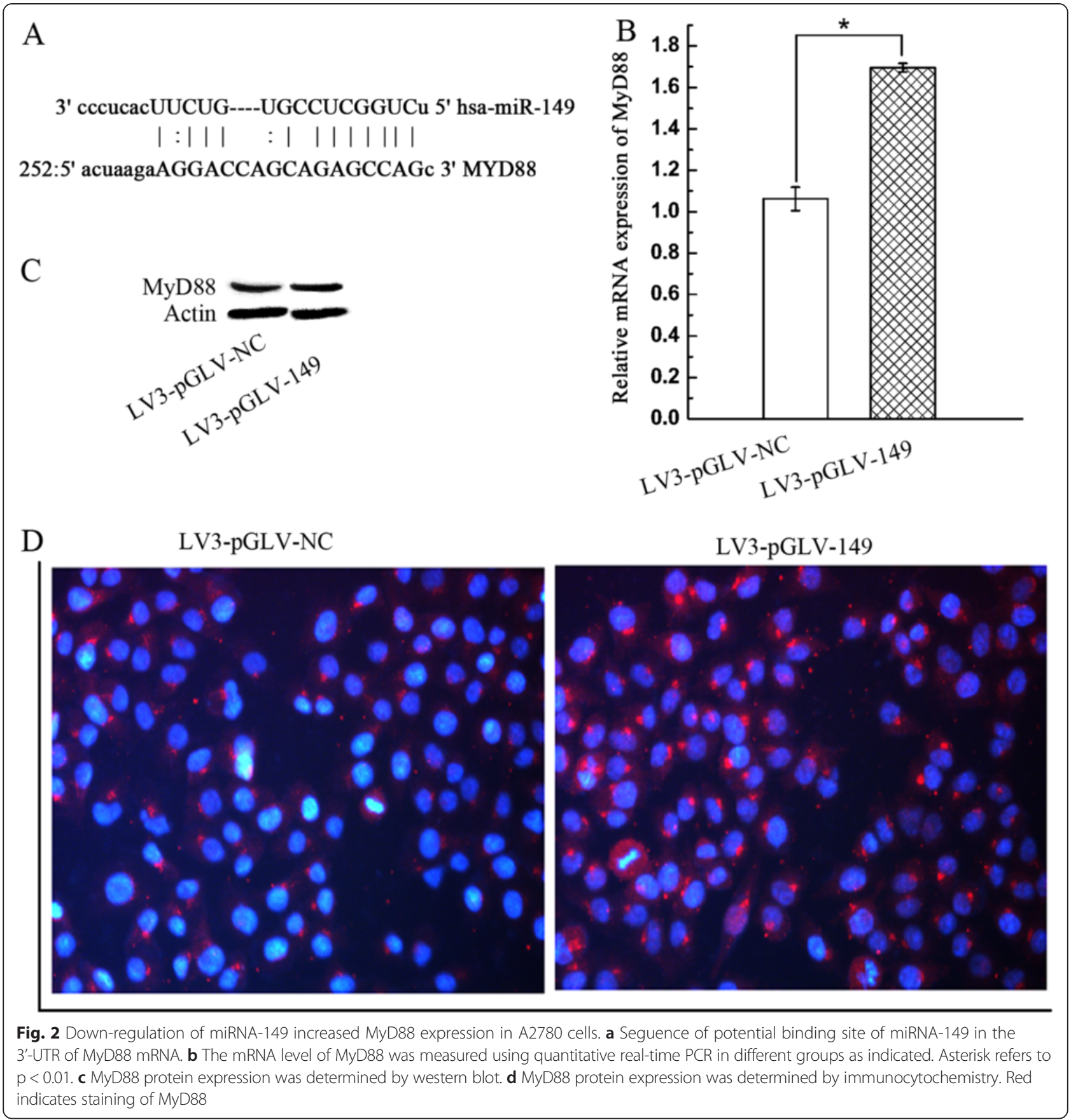

was evaluated using both real-time PCR, western blot and immunocytochemistry. MiRNA-149 was capable of altering MyD88 expression at the mRNA level in these cells and consequently was able to up-regulate MyD88 mRNA expression by 1.67 fold as compared to the negtive control (Fig. 2b). Furthermore, the overexpression of MyD88 was verified by western blot and immunohistochemistry (Fig. 2c and d). Collectively, the data indicate that miRNA-149 has the potential to regulate MyD88 expression in ovarian cancer cells.

\section{Decreased sensitivity of A2780 cells to paclitaxel} treatment after over-expression of MyD88

To determine the effects of elevated MyD88 expression in ovarian cancer, MyD88 was over-expressed in ovarian cancer A2780 cells using a lentiviral vector. Over-expression 
was confirmed by real-time PCR (Fig. 3a). MyD88overexpressing cells were refractory to growth inhibition by paclitaxel when compared to the control (Fig. 3b).

\section{Effects of miRNA-149 down-regulation on the cell cycle of A2780 cells}

It is well known that paclitaxel arrests the cell cycle at the G2 phase. To analyze the impact of miRNA-149 expression on paclitaxel's interference with the cell cycle in A2780 cells, DNA flow cytometric analysis was performed to determine the effect of paclitaxel on the cell cycle of A2780 cells with different expression levels of miRNA-149. A G2 phase increase was found in A2780 cells with miRNA-149 down-regulation and NC cells after treatment with paclitaxel (Fig. 4a and b). The G2 phase fold change was significantly decreased in cells with miRNA-149 down-regulation (Fig. 4c).

\section{Regulation of apoptosis by miRNA-149 down-regulation in A2780 cells}

Cells were treated with paclitaxel for $48 \mathrm{~h}$ prior to the measurement of apoptotic cells with Annexin V. As shown in Fig. 5a and b, a significant decrease in the percentage of apoptotic cells was observed in A2780 cells with miRNA-149 down-regulation $(\mathrm{P}<0.01)$. Down-regulation of miRNA-149 decreased the expression of Bax in A2780 cells and increased the expression of Bcl-2 (Fig. 5c and d). These results suggest that miRNA-149 may be associated with the cell apoptosis induced by paclitaxel in A2780 cells.

\section{Down-regulation of miRNA-149 promotes the migration of $A 2780$ cells}

As shown in Fig. 6a, A2780 cells migrated faster when miRNA-149 was down-regulated, as indicated by the number of migrated cells within a fixed time (Fig. 6b). These data suggest that down-regulation of miRNA-149 may promote the migration of A2780 cells.

\section{Discussion}

An increasing number of studies suggests that miRNAs play important roles in diverse biological processes, such as development, cell proliferation, apoptosis, fat metabolism, and oncogenesis [12]. Over the years, attention has focused on the role of miRNAs in reversing drug resistance and regulating the sensitivity of cancer cells to chemotherapeutants $[13,14]$. Dysregulated expression of various miRNAs has been found in ovarian carcinoma. Dysregulation of the microRNA let-7e and downregulation of miR-30c, miR-130a, and miR-335 indicate direct involvement of some miRNAs in the development of chemoresistance [15]. Down-regulation of miR-21 promotes apoptosis and chemosensitivity in ovarian cancer [16]. MiRNA-370 [17], miRNA-93 [18], and miRNA-100 [19] are related to the chemosensitivity of ovarian cancer.

Aberrant expression of miR-149 has been reported in many cancers including colorectal cancer [20], nasopharyngeal carcinoma [21], clear-cell renal cell carcinoma [22], prostate cancer [23], and gastric cancer [24]. Li et al. [25] found that over-expression of miR-149 inhibited glioblastoma cell proliferation and migration. As a methylation-sensitive miRNA, miR-149 plays an important role as a tumor suppressor in colorectal cancer with prognostic and therapeutic implications [26]. However, the relationship between miRNA-149 expression and the sensitivity to paclitaxel in ovarian cancer remains unknown. Our results show that down-regulation of miRNA-149 decreases the sensitivity of A2780 cells to paclitaxel treatment.

MyD88 is a key molecular cohesion molecule in the Toll-like receptor (TLR) signaling pathway. Elevated
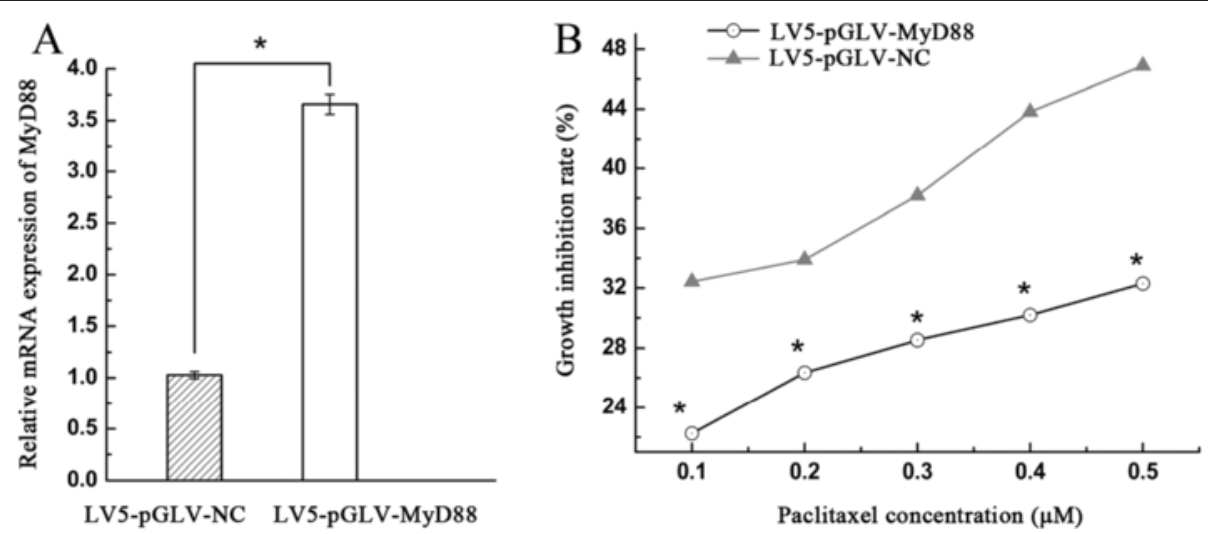

Fig. 3 Inhibition of cell growth by paclitaxel was determined in A2780 cells after over-expression of the MyD88 gene. Paclitaxel treatment was conducted for $48 \mathrm{~h}$ with the indicated concentrations. a The mRNA level of MyD88 was measured using quantitative real-time PCR in different groups (experimental vs. NC control). b The inhibition of cell growth by paclitaxel was determined in A2780 cells after MyD88 overexpression. Asterisk refers to $p<0.01$ 


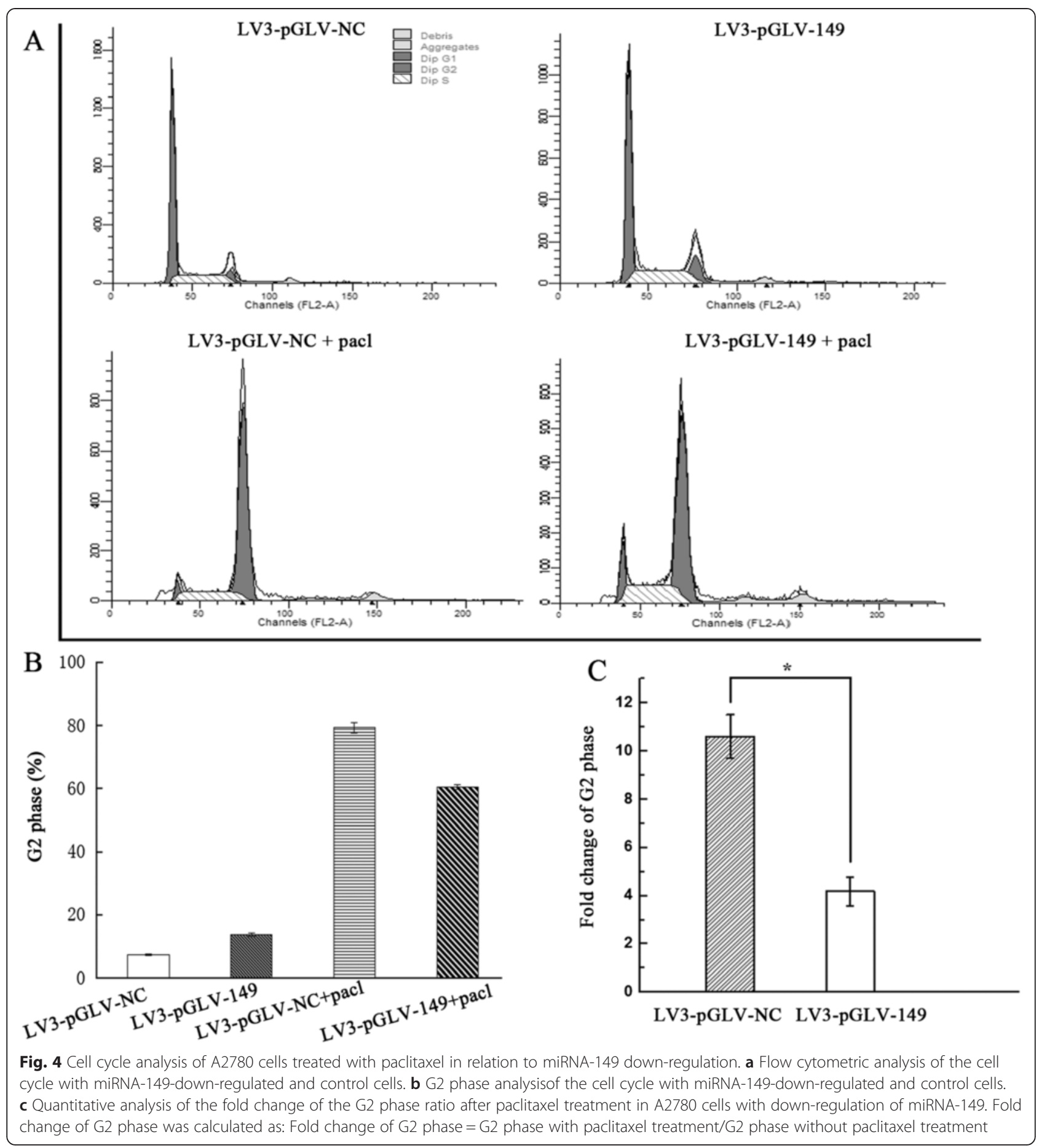

MyD88 expression has been found in parenchymal cells in various types of cancer [27-29]. Expression of MyD88 was elevated in more than $70 \%$ of patients with EOC and has been considered as an indicator of tumor metastasis and paclitaxel chemoresistance, in addition to a factor for significantly poor prognosis $[30,31]$. Overexpression of MyD88 decreases the sensitivity to paclitaxel in ovarian cancer and hepatocellular carcinoma cells [32, 33].

In the present study, expression of miRNA-149 in A2780 cells was decreased by specific inhibitor using lentiviral vectors. miRNA-149 down-regulation resulted in increased expression of MyD88 in A2780 cells. The results are consistent with previous results that over- 


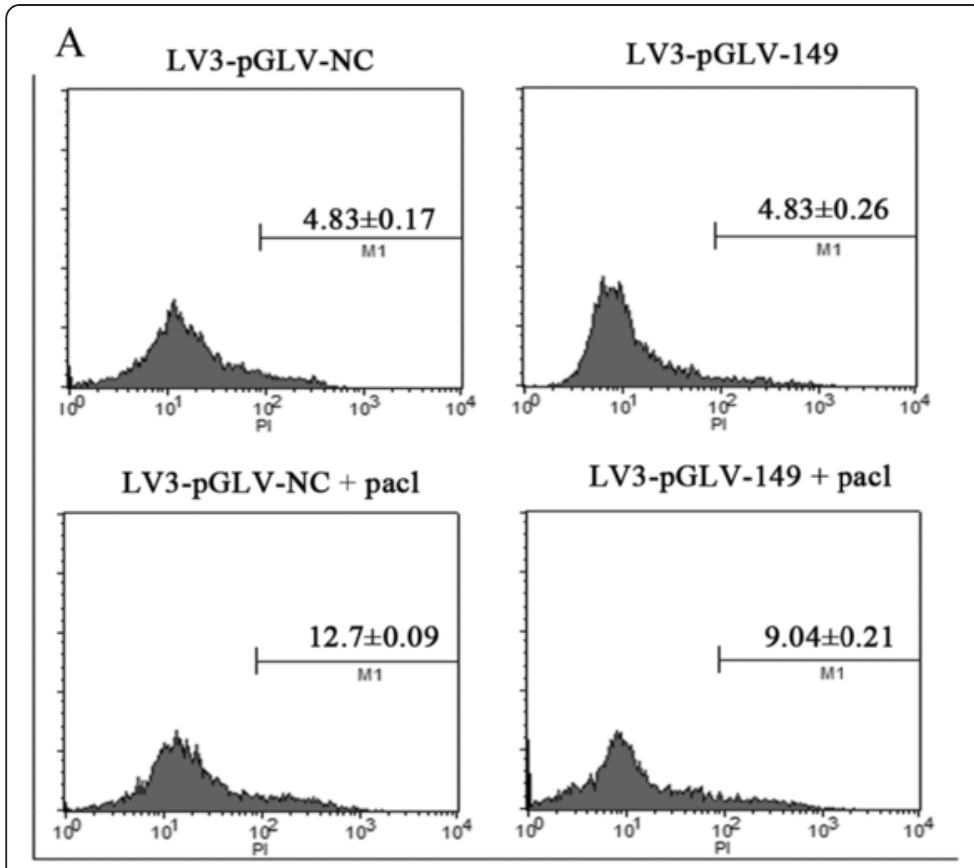

B

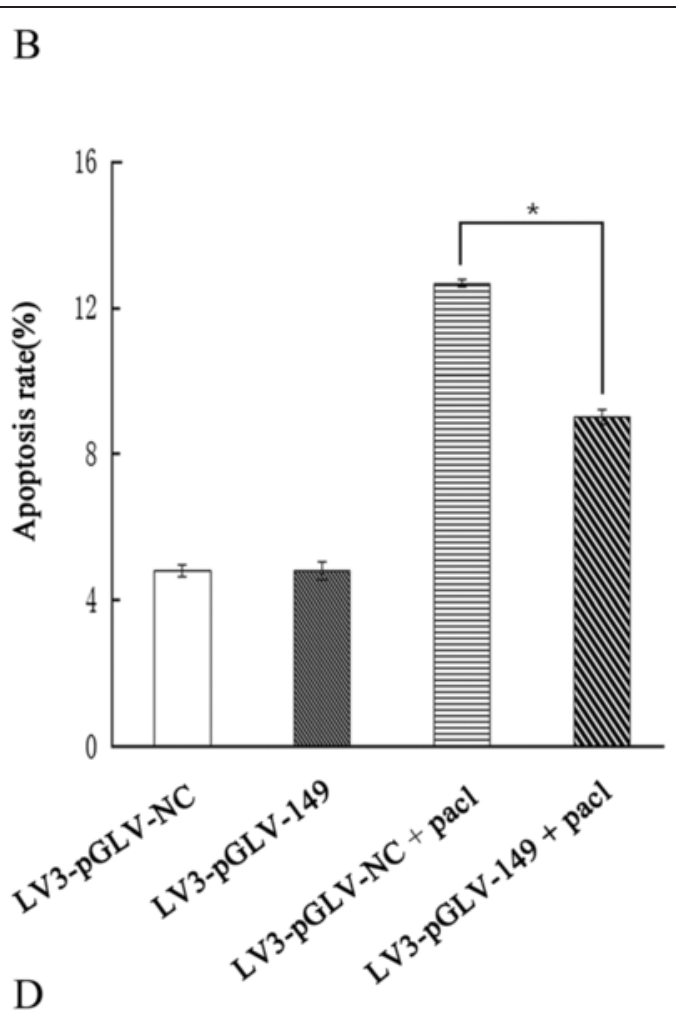

C

D
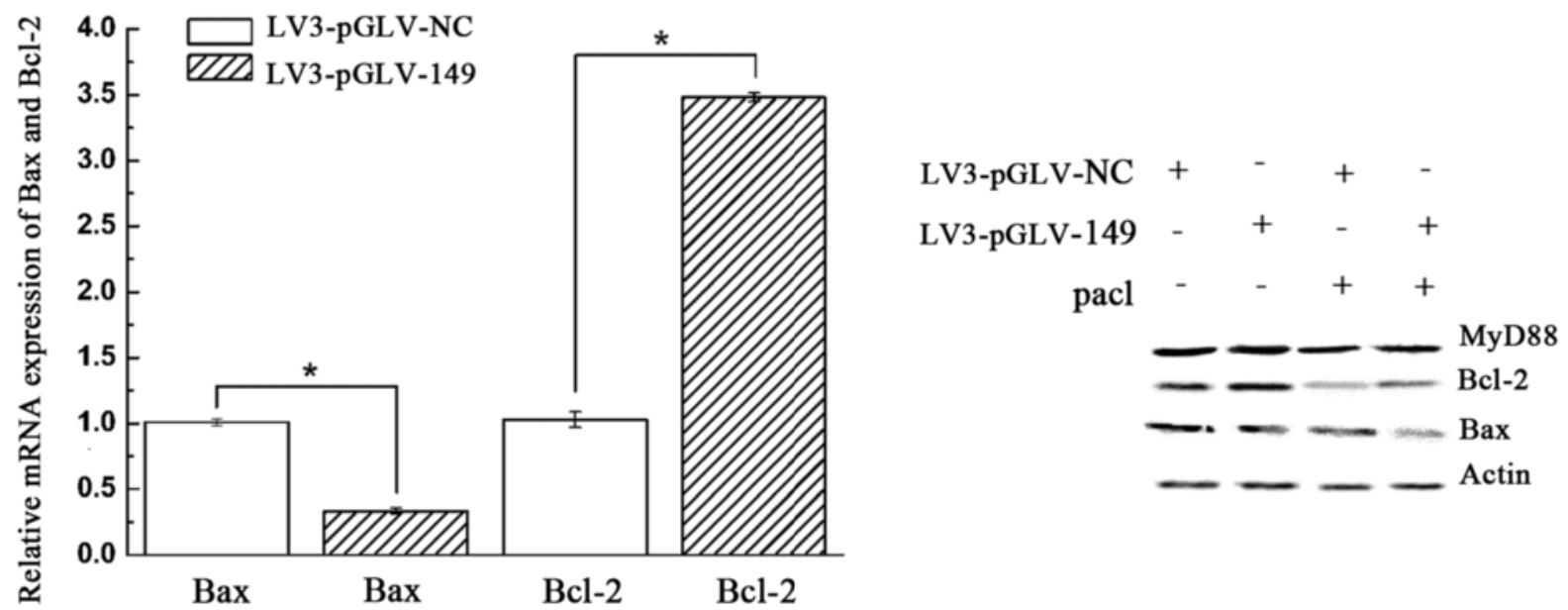

Fig. 5 Analysis of apoptosis in A2780 cells with miRNA-149 down-regulation. a Apoptosis in miRNA-149-down-regulated A2780 cells was analyzed by Annexin V-PE staining after treatment with paclitaxel. Data are presented as the mean \pm SD of three independent experiments. $\mathbf{b}$ Apoptosis rates of miRNA-149-down-regulated and control cells. Asterisk refers to $p<0.01$. c Real-time PCR analysis of Bax and Bcl-2 mRNA expression. The results were normalized to the amount of $\beta$-actin. Each value represents the average of 3 independent experiments. Asterisk refers to $p<0.01$. d Western blot analysis of Bcl-2, Bax and MyD88 proteins expression in each group. $\beta$-actin expression served as the loading control

expression of miR-149 in RAW264.7 cells was associated with decreased MyD88 at the protein level [10]. In the presence of paclitaxel, the proliferation of A2780 cells was significantly inhibited in the control group, suggesting that miRNA-149 down-regulation may decrease the sensitivity of A2780 ovarian cancer cells to paclitaxel treatment. Furthermore, the sensitivity to paclitaxel was decreased in MyD88 over-expressing A2780 cells.
Paclitaxel is an effective anti-cancer drug against a variety of cancers. Paclitaxel reduces the dynamicity of the mitotic spindle, causing G2/M cell cycle arrest [34]. In our study, we analyzed the cell cycle of A2780 cells with miRNA-149 down-regulation after treatment with paclitaxel for $48 \mathrm{~h}$. The G2/M phase transition was decreased significantly in A2780 cells in the transduced group compared to the control group. The reduction in 


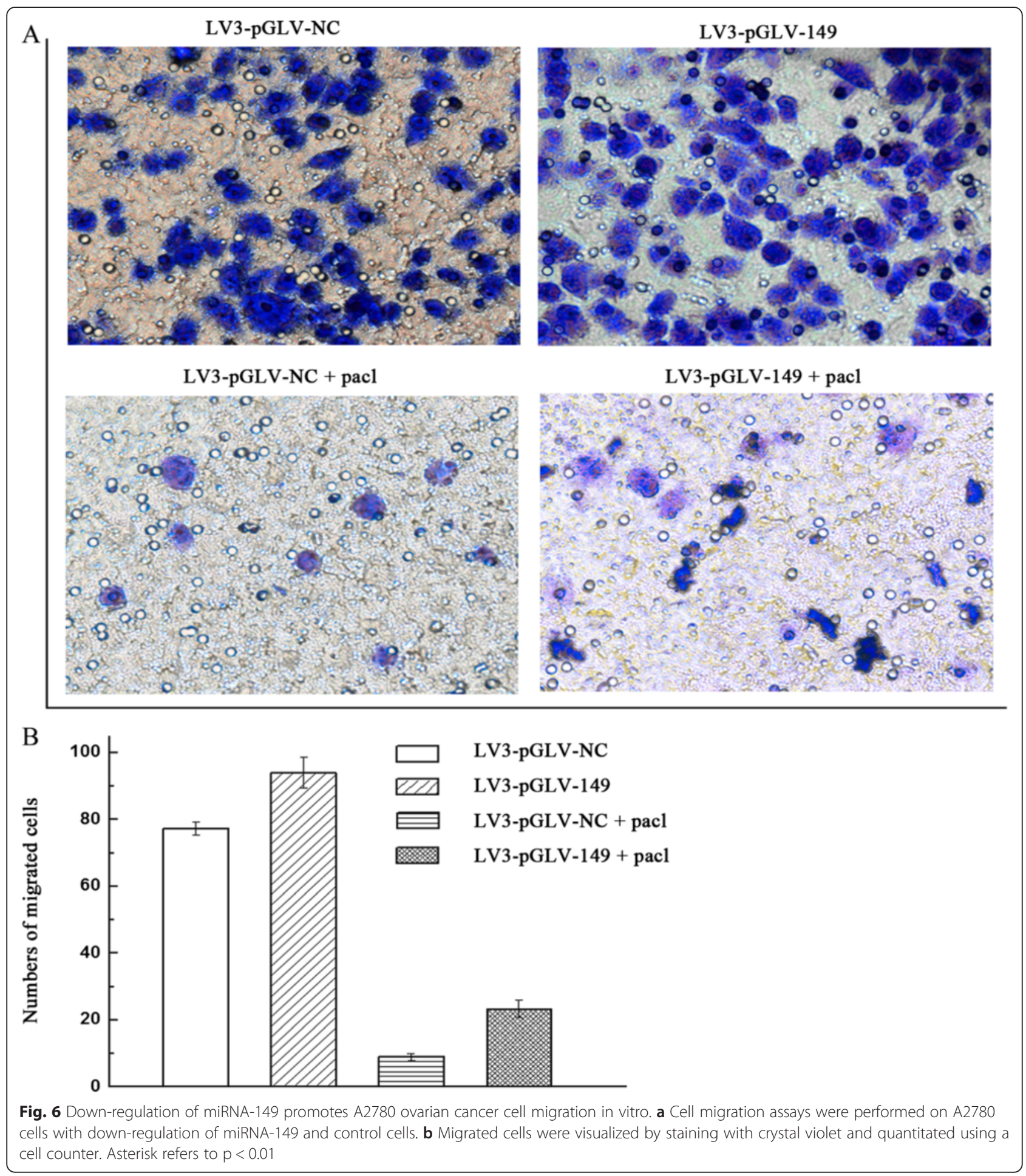

the number of cells at G2 phase and the accumulation of cells at the G0/G1 phase suggest that miRNA-149 is associated with paclitaxel chemosensitivity.

Depending on the cell type and drug, cells undergo apoptosis during mitotic arrest or abnormal mitosis [35]. Paclitaxel directly induces apoptosis of several types of tumor cells through a variety of mechanisms, such as phosphorylation of $\mathrm{Bcl}-2$, activation of caspase-3 and caspase- 9 , and the mitogen-activated protein kinase signal transduction pathway [36-38]. In the present study, flow cytometric assays were used to detect the apoptosis of A2780 cells after down-regulation of miRNA-149. We 
found that down-regulation of miRNA-149 decreased the apoptosis induced by paclitaxel when compared to the control group. Furthermore, we showed that downregulation of miRNA-149 in A2780 cells enhanced the expression of the anti-apoptotic protein $\mathrm{Bcl}-2$ and inhibited the expression of the pro-apoptotic protein bax, which may have led to paclitaxel resistance. Our previous study demonstrated that [11] MyD88 was involved in anti-apoptosis and drug resistance through the alteration of bax and bcl-2 levels.

In this study, we have shown that reduced expression of miRNA-149 enhanced the migration of A2780 cells. Chan et al. showed that down-regulation of microRNA-149 suppressed cell migration/invasion and metastasis in breast cancer by targeting migration and invasion-related genes [39]. Taken together, our findings suggest that miR-149 facilitates the migration of ovarian cancer cells through regulation of MyD88.

\section{Conclusions}

Our data demonstrate that miRNA-149 is associated with the cellular response to paclitaxel through regulation of MyD88 in ovarian cancer cells. These findings provide novel insights into the role of miR-149 in the chemosensitivity of human ovarian cancer and indicate that miR-149 could be a putative drug target for therapeutic intervention.

\section{Competing interests}

The authors declare that they have no competing interests.

\section{Authors' contributions}

YZ participated in the design of the study, carried out the molecular genetic studies, and drafted the manuscript. FX participated in the design of the study and performed the statistical analysis. RW involved in revising the manuscript critically. JX carried out the immunoassays. ZN participated in the sequence alignment. JJ participated in cell culture. XK conceived of the study, and participated in its design and coordination and helped to draft the manuscript. All authors read and approved the final manuscript.

\section{Acknowledgements}

This study was supported by grants from the Shanghai Municipal Health Bureau of China (no. 20134274) and Putuo Hospital, Shanghai University of Traditional Chinese Medicine (no. 2013GQ012I).

Received: 4 June 2015 Accepted: 8 July 2015

Published online: 30 July 2015

\section{References}

1. Kim A, Ueda $Y$, Naka T, Enomoto T. Therapeutic strategies in epithelial ovarian cancer. J Exp Clin Cancer Res. 2012;31:14.

2. Gottesman MM. Mechanisms of cancer drug resistance. Annu Rev Med. 2002;53:615-27.

3. Mozzetti S, Ferlini C, Concolino P, Filippetti F, Raspaglio G, Prislei S, et al. Class III beta-tubulin overexpression is a prominent mechanism of paclitaxel resistance in ovarian cancer patients. Clin Cancer Res. 2005;11(1):298-305

4. Filippetti F, Martinelli E, Ferrandina G, Gallo D, Ranelletti FO, Scambia G, et al. Bcl-2 down-Regulation is a novel mechanism of paclitaxel resistance. Mol Pharmacol. 2003;64:51-8.

5. Liu Z, Zhu G, Getzenberg RH, Veltri RW. The upregulation of PI3K/Akt and MAP kinase pathways is associated with resistance of microtubule-targeting drugs in prostate cancer. J Cell Biochem. 2015. doi:10.1002/jcb.25091.
6. Baek D, Villen J, Shin C, Camargo FD, Gygi SP, Bartel DP. The impact of micrornas on protein output. Nature. 2008;455(7209):64-71.

7. Cui $Q$, Yu Z, Purisima EO, Wang E. Principles of microrna regulation of a human cellular signaling network. Mol Syst Biol. 2006;2:46.

8. Inui M, Martello G, Piccolo S. MicroRNA control of signal transduction. Nat Rev Mol Cell Biol. 2010;11:252-63.

9. Cui Q, Yu Z, Purisima EO, Wang E. Microrna regulation and interspecific variation of gene expression. Trends Genet. 2007;23(8):372-5.

10. Xu G, Zhang Z, Xing Y, Wei J, Ge Z, Liu X, et al. Microrna-149 negatively regulates tlr-triggered inflammatory response in macrophages by targeting myd88. J Cell Biochem. 2014;115(5):919-27.

11. Xiang F, Wu R, Ni Z, Pan C, Zhan Y, Xu J, et al. MyD88 expression is associated with paclitaxel resistance in lung cancer A549 cells. Oncol Rep. 2014;32(5):1837-44.

12. Ishihara T, Seki N, Inoguchi S, Yoshino H, Tatarano S, Yamada Y, et al. Expression of the tumor suppressive mirna-23b/27b cluster is a good prognostic marker in clear cell renal cell carcinoma. J Urol. 2014;192(6):1822-30.

13. Ma MT, He M, Wang $Y$, Jiao XY, Zhao L, Bai XF, et al. Mir-487a resensitizes mitoxantrone $(\mathrm{mx})$-resistant breast cancer cells ( $\mathrm{mcf}-7 / \mathrm{mx}$ ) to $\mathrm{mx}$ by targeting breast cancer resistance protein (bcrp/abcg2). Cancer Lett. 2013;339(1):107-15.

14. To KK, Zhan Z, Litman T, Bates SE. Regulation of abcg2 expression at the 3' untranslated region of its mrna through modulation of transcript stability and protein translation by a putative microrna in the s1 colon cancer cell line. Mol Cell Biol. 2008;28(17):5147-61.

15. Sorrentino A, Liu CG, Addario A, Peschle C, Scambia G, Ferlini C. Role of micrornas in drug-resistant ovarian cancer cells. Gynecol Oncol. 2008;111(3):478-86.

16. Chan JK, Blansit K, Kiet T, Sherman A, Wong G, Earle C, et al. The inhibition of miR-21 promotes apoptosis and chemosensitivity in ovarian cancer. Gynecol Oncol. 2014;132(3):739-44.

17. Chen XP, Chen YG, Lan JY, Shen ZJ. MicroRNA-370 suppresses proliferation and promotes endometrioid ovarian cancer chemosensitivity to cDDP by negatively regulating ENG. Cancer Lett. 2014;353(2):201-10.

18. Fu X, Tian J, Zhang L, Chen Y, Hao Q. Involvement of microrna-93, a new regulator of pten/akt signaling pathway, in regulation of chemotherapeutic drug cisplatin chemosensitivity in ovarian cancer cells. FEBS Lett. 2012;586(9):1279-86.

19. Peng DX, Luo M, Qiu LW, He YL, Wang XF. Prognostic implications of microRNA-100 and its functional roles in human epithelial ovarian cancer. Oncol Rep. 2012;27(4):1238-44.

20. Ng EK, Chong WW, Jin H, Lam EK, Shin VY, Yu J, et al. Differential expression of micrornas in plasma of patients with colorectal cancer: A potential marker for colorectal cancer screening. Gut. 2009;58(10):1375-81.

21. Luo Z, Zhang L, Li Z, Li X, Li G, Yu H, et al. An in silico analysis of dynamic changes in microrna expression profiles in stepwise development of nasopharyngeal carcinoma. BMC Med Genomics. 2012:5:3.

22. Liu H, Brannon AR, Reddy AR, Alexe G, Seiler MW, Arreola A, et al. Identifying mrna targets of microrna dysregulated in cancer: With application to clear cell renal cell carcinoma. BMC Syst Biol. 2010;4:51.

23. Schaefer A, Jung M, Mollenkopf HJ, Wagner I, Stephan C, Jentzmik F, et al. Diagnostic and prognostic implications of microRNA profiling in prostate carcinoma. Int J Cancer. 2010;126(5):1166-76.

24. Wang Y, Zheng X, Zhang Z, Zhou J, Zhao G, Yang J, et al. Microrna-149 inhibits proliferation and cell cycle progression through the targeting of zbtb2 in human gastric cancer. PLoS One. 2012;7(10):e41693.

25. Li D, Chen P, Li XY, Zhang LY, Xiong W, Zhou M, et al. Grade-specific expression profiles of mirnas/mrnas and docking study in human grade i-iii astrocytomas. OMICS. 2011;15(10):673-82.

26. Wang F, Ma YL, Zhang P, Shen TY, Shi CZ, Yang YZ, et al. Sp1 mediates the link between methylation of the tumour suppressor mir-149 and outcome in colorectal cancer. J Pathol. 2013;229(1):12-24.

27. Wang EL, Qian ZR, Nakasono M, Tanahashi T, Yoshimoto K, Bando Y, et al. High expression of toll-like receptor 4/myeloid differentiation factor 88 signals correlates with poor prognosis in colorectal cancer. $\mathrm{Br} \mathrm{J}$ Cancer. 2010;102(5):908-15.

28. Xiang WQ, Feng WF, Ke W, Sun Z, Chen Z, Liu W. Hepatitis b virus x protein stimulates il-6 expression in hepatocytes via a myd88-dependent pathway. J Hepatol. 2011;54(1):26-33. 
29. Szajnik M, Szczepanski MJ, Czystowska M, Elishaev E, Mandapathil M, Nowak-Markwitz E, et al. TIr4 signaling induced by lipopolysaccharide or paclitaxel regulates tumor survival and chemoresistance in ovarian cancer. Oncogene. 2009;28(49):4353-63.

30. Zhou M, McFarland-Mancini MM, Funk HM, Husseinzadeh N, Mounajjed T, Drew AF. Toll-like receptor expression in normal ovary and ovarian tumors. Cancer Immunol Immunother. 2009;58(9):1375-85.

31. Wang AC, Su QB, Wu FX, Zhang XL, Liu PS. Role of tru for paclitaxel chemotherapy in human epithelial ovarian cancer cells. Eur J Clin Invest. 2009;39(2):157-64.

32. Kelly MG, Alvero AB, Chen R, Silasi DA, Abrahams VM, Chan S, et al. Trr-4 signaling promotes tumor growth and paclitaxel chemoresistance in ovarian cancer. Cancer Res. 2006;66(7):3859-68.

33. Liang B, Chen R, Wang T, Cao L, Liu Y, Yin F, et al. Myeloid differentiation factor 88 promotes growth and metastasis of human hepatocellular carcinoma. Clin Cancer Res. 2013;19(11):2905-16.

34. Holleman A, Chung I, Olsen RR, Kwak B, Mizokami A, Saijo N, et al. Mir-135a contributes to paclitaxel resistance in tumor cells both in vitro and in vivo. Oncogene. 2011;30(43):4386-98.

35. Shi J, Orth JD, Mitchison T. Cell type variation in responses to antimitotic drugs that target microtubules and kinesin-5. Cancer Res. 2008;68(9):3269-76.

36. Haldar S, Chintapalli J, Croce CM. Taxol induces bel-2 phosphorylation and death of prostate cancer cells. Cancer Res. 1996:56(6):1253-5.

37. Perkins C, Kim CN, Fang G, Bhalla KN. Overexpression of Apaf-1 promotes apoptosis of untreated and paclitaxel- or etoposide-treated HL-60 cells. Cancer Res. 1998;58(20):4561-6.

38. Goncalves A, Braguer D, Carles G, Andre N, Prevot C, Briand C. Caspase-8 activation independent of CD95/CD95-L interaction during paclitaxel-induced apoptosis in human colon cancer cells (HT29-D4). Biochem Pharmacol. 2000;60(11):1579-84.

39. Chan SH, Huang WC, Chang JW, Chang KJ, Kuo WH, Wang MY, et al. Microrna-149 targets git1 to suppress integrin signaling and breast cancer metastasis. Oncogene. 2014;33(36):4496-507.

\section{Submit your next manuscript to BioMed Central and take full advantage of:}

- Convenient online submission

- Thorough peer review

- No space constraints or color figure charges

- Immediate publication on acceptance

- Inclusion in PubMed, CAS, Scopus and Google Scholar

- Research which is freely available for redistribution 